\title{
RE-READING DESIGN: CULTURAL ANALOGIES FOR INSPIRATION IN INTERACTION DESIGN
}

\author{
Oğuzhan ÖZCAN \\ Design Lab, Koç Üniversitesi, Türkiye \\ https://orcid.org/0000-0002-4410-3955 \\ oozcan@ku.edu.tr \\ Ahmet GÜZERERLER \\ Design Lab, Koç Üniversitesi, Türkiye \\ https://orcid.org/0000-0001-7574-7000 \\ aguzererler@ku.edu.tr
}

\begin{abstract}
Designers systematically seek inspiration from various sources from different domains and expand their repertoire of paradigms to foster their designs. However, designers usually do not explore the full potential of their inspiration sources by establishing surface level and close domain analogies regardless of their experience. We think that the process of finding deep and distant domain analogies could be made more understandable for novice designers and less time consuming for professionals with an inspiration/ideation practice for innovation. We discovered that decontextualizing the inspiration source and deconstructing its perceived meaning into fragments lead designers to explore new connections with inspiration source and discover new inspirational points. Here, in this paper, we re-introduce our re-reading in design practice from our previous studies and examine whether it can be a complimentary inspiration/ideation practice for designers to deconstruct conventional paradigms and create deep and distant domain analogies more comfortably.
\end{abstract}

Keywords: Analogy, inspiration, re-reading, deconstruction, design theory, interactive system

\section{TASARIMDA YENIDEN OKUMA: ETKİLEŞIMM TASARIMINDA İLHAM KAYNAĞI OLARAK KÜLTÜREL ANALOJILER}

ÖZ

Tasarımcılar ilham bulmak için sistematik bir şekilde çeşitli alanlardan kaynaklar kullanmakta ve paradigma dağarcıklarını genişletmektedirler. Fakat tasarımcılar genelde bu süreçte ilham kaynaklarıyla yüzey düzeyi ve yakın alan analojileri kurmadıkları için fikirlerinin tam potansiyelini keşfedememektedirler. İlham kaynağını bağlamından bağımsız değerlendirerek ve anlamını yeniden inşaa ederek tasarımcıların esinleninen ile yeni bağlantılar ve yeni ilham noktaları keşfettiğini gördük. İnovasyon için ilham / düşünce uygulaması yapılırken, bu derin ve uzak alan analojileri bulma sürecinin yeni tasarımcılar için daha anlaşılır, profesyoneller için ise daha az zaman gerektiren bir hale getirilebileceğini düşünüyoruz. Bu yazıda, daha önceki çalışmalarımızdan olan tasarım pratiğinde yeniden okuma'yı baştan tanıtıyor ve bunun ilham / düşünce uygulamasında tasarımcılara geleneksel paradigmaları bozmak, derin ve uzak alan analojileri daha rahat bir şekilde kurmalarındaki etkisini inceliyoruz

Anahtar Kelimeler: Analoji, ilham, yeniden okuma, dekonstrüksiyon, tasarım teorisi, interaktif sistem

Submit Date: 11.10.2017, Acceptance Date: 21.03.2018, DOI NO: 10.7456/10802100/015

Research Article - This article was checked by Turnitin

Copyright $($ ) The Turkish Online Journal of Design, Art and Communication 
The Turkish Online Journal of Design, Art and Communication - TOJDAC

ISSN: 2146-5193, April 2018 Volume 8 Issue 2, p. 364-375

\section{INTRODUCTION}

Designers, like all humans, are influenced by objects, situations, people and their memories and experiences (Goldschmidt and Smolkov, 2006; Golçalves et al., 2013). These influences often mentally stimulate designers and designers advance these stimulations to a design idea; this process is called 'inspiration'. Inspiration has an important role in the design process, especially for innovation; sometimes an inspiration is the starting point for a design, or a driving idea during the design process. Therefore, designers systematically seek inspiration from various sources and domains to expand their repertoire of paradigms instead of waiting for random inspirations (Biskjaer et al., 2010). As designers' solution space expand; designers' possibilities for generating innovative design ideas increase (Golçalves et al., 2011).

Some researchers feel that ideation and inspiration processes are thought to be different by some researchers; however, two phases are closely inter-related, and there are no distinct boundaries (Brown, 2008). Most designers start the idea generation as soon as they encounter an inspiration source. At this point, designers mostly begin using 'analogies' almost spontaneously, and analogy becomes the bridge between inspiration sources and the design idea (Ball et al., 2004). Analogy is defined as studying similarities such as principles, functions, shapes between known paradigms (inspiration source) and an unknown domain (design domain) and transferring selected findings to the design domain for creative ideas and solutions (Gentner and Markman, 1997; Golçalves et al., 2013; Hey et al., 2008). In terms of inspiration, researchers argue that analogy is the designers' fundamental reflex for innovation (Ball et al., 2004). In other words, it provides different lenses for designers to solve design problems and those lenses can be keys to innovation and creativity.

However, designers usually do not explore the full potential of analogies in their designs. In recent research, both professionals and novices showed a tendency to search for analogies from 'close domain' (conceptually similar/related) sources for different reasons (Golçalves et al., 2011). Conversely, research indicates that creativity and novelty increase in design as the conceptual distance between the inspiration source and the design domain increases and connections between paradigms get deepen (Graham, 2003; Gentner and Markman, 1997).

Different reasons cause this situation for both professional and novice designers. Professionals often do not search for distant domain analogies since they may think that searching distant domain analogies is inefficient in terms of time and effort due to the ambiguity of the result. On the other hand, many novice designers may not have the skills to create deep, distant domain analogies (Paulos and Jenkins, 2005). Consequently, there are different reasons for novice and professional designers difficulty in using distant domain analogies. We think that the process of finding distant domain analogies could be made more understandable for novice designers and less time consuming for professionals with an inspiration/ideation practice to obtain better results in the innovation process.

In our previous studies, we applied the inspirational design practice, called 're-reading in design' (Özcan, 2005; Özkan and Doğan, 2013; Versos and Coelho, 1997). We discovered that decontextualizing the inspiration source and deconstructing its perceived meaning into fragments lead designers to explore new connections regarding the source and discover new inspirational points. Furthermore, we realized that these findings helped designers construct deep and distant domain analogies that lead to unconventional and innovative designs. Here, in this paper, we introduce our 're-reading in design' practice from our previous studies and examine whether it can be a complimentary inspiration and ideation practice for designers to deconstruct conventional paradigms and create deep and distant domain analogies more comfortably. Furthermore, we outline theoretical background in re-reading in design and provide three case studies in order to explore the nature of our alternative method, demonstrate its steps in practice and define its contribution to designers and to the field. In these case studies, we worked with different small groups (5-10) of students and observed their design process using re-reading in design.

Submit Date: 11.10.2017, Acceptance Date: 21.03.2018, DOI NO: 10.7456/10802100/015

Research Article - This article was checked by Turnitin

Copyright $($ ) The Turkish Online Journal of Design, Art and Communication 
Our case studies are pilots for evaluating the method and gather the knowledge for designing further quantitative studies. We believe that quantitative study could be done without this theoretical discussion and this pre-analysis.

\section{SOURCES OF INSPIRATION AND ANALOGICAL CONNECTIONS}

Re-reading in design practice is heavily based on inspiration and analogies. An understanding of rereading in design and its contributions can be achieved with an exploration of inspiration sources and analogies:

\section{Inspiration Sources}

As stated, designers expand their repertoire of paradigm by searching for inspiration (Halskov, 2010). Inspiration source can be encountered anytime while doing anything. Most designers seek inspiration sources within arts, nature, urban life and city, Internet, people and existing artefacts to increase the chance of getting inspiration.

The Arts are a combination of products of creative minds. Each piece is a combination of ideas and symbols. Symbols represent different stories, and these could trigger many associations with the source and design problem (Behrens, 1998). Besides, artworks may carry the clues for the future designs due to their unconstrained creation space.

Nature holds the most fertile sources of inspiration, not just for design, but also for science. Nature shelters beings that evolved and refined their biological designs over million years. In order to harvest this knowledge of nature, designers, bio-designers and engineers examine internal and external structures of living creatures and create analogies such as sharkskin inspired swimsuit, or a woodpecker inspired ice axe (Ladato, 2005).

Urban life and the city are full of inspirational sources such as buildings, history museums, movie theatres and people. We can mainly divide urban life into sub categories like public places, community, infrastructure and traversal (Sanders, 2005). All of these establish the urban culture. Therefore, each city has different dynamics and soul and has different inspiration sources.

People are precious sources of inspiration as well. There are different ways to utilize people as inspiration sources. For example, Bill Gaver (1999) presented "Cultural Probes" in which he benefited users/people as inspiration sources instead of information sources (Gaver, 1999). Furthermore, other researchers extended the probe approach such as, technology probes, children probes and urban probes, for to different contexts for collecting inspiration from for specific areas (Hutchinson et al., 2003; Moser et al., 2011; Sanders, 2005). Also, collaborative design practices like, 'make tools', design workshops and design cards, consider users and colleagues both inspiration and information sources (Schröder, 2010).

The Internet provides a huge database of knowledge and experience, in which one can seek, wander and be lost like a digital flaneur and harvest inspiration sources.

Obsolete artefacts were designed to solve a problem in the past. Those artefacts, which can be found within patent archives, museums and media archaeology books, may provide different perspectives for designers for design problems. Many designers are inspired from obsolete concepts and solutions -retro culture is an example for the situation-. In addition to permanent sources such as patents, books, examples in museums, Wyche, Sengers, and Grinter introduced memory scrapbook to understand the past by digging the elders' memories and recording (Wyche et al., 2006). 
After examination of the potential inspiration sources, we can conclude that designers mostly search inspiration on sources, which conveys different concepts, principles and subtexts such as cultural traditions, arts or people. Since contextually rich sources contains links to different concepts that designers could use in their ideation processes. Therefore, they generally trigger designers' creativity more since designers can link different through these inspiration sources. When designers are inspired by a source, they spontaneously start to establish analogies as a reflex for creating new design concept (Ball et al., 2004).

\section{Understanding Analogies}

Designers use analogies to study similarities between a known domain (source domain) and an unknown domain (design domain) establish connections to understand the unknown domain (Gentner and Markman, 1997). (See Table 1 for complete terms for analogies) These connections are used to create a knowledge transfer from a source domain to a target domain. This knowledge transfer provides designers an opportunity to understand the unknown domain from a different perspective and explore new principles and features (Casakin, 2004).

Designers complete this process of knowledge transfer in two steps: (1) 'identification and retrieval' and (2) 'mapping and transference' (Casakin, 2004). In the identification and retrieval phase, designers probe into the source and its domain and study the source to get enough knowledge to create analogies. Casakin (2004) argued that designers extract features, define principles and suggest keywords regarding the source. After the identification and retrieval phase, designers start to map the extracted features and principles between the source and the target domain. Designers start to establish links and explore relationships to create analogies; this process is critical for creating the new design concepts for innovation (Dorst and Royakkers, 2006;, Gick and Holyoak, 1980).

Table 1. Terms for understanding analogies

\begin{tabular}{|c|c|}
\hline Term & Refers to \\
\hline Target domain & \multirow{3}{*}{ The domain in which the design concept is defined } \\
\hline Unknown domain & \\
\hline Design domain & \\
\hline Source domain & \multirow[b]{2}{*}{ The domain in which the investigated source is defined } \\
\hline Unknown domain & \\
\hline Structural analogy & $\begin{array}{l}\text { Establishing strong relations between the source and the target domain in } \\
\text { terms of principles }\end{array}$ \\
\hline Surface level analogy & No deep connection among the source domain principles. \\
\hline Mental hops & \multirow{3}{*}{ Big conceptual distance between source and the target domain. } \\
\hline $\begin{array}{l}\text { Distant domain } \\
\text { analogy }\end{array}$ & \\
\hline Inter domain analogy & \\
\hline Mental leaps & \multirow{3}{*}{ Small conceptual distance between source and the target domain. } \\
\hline $\begin{array}{l}\text { Near/close domain } \\
\text { analogy }\end{array}$ & \\
\hline Intra domain analogy & \\
\hline
\end{tabular}

Submit Date: 11.10.2017, Acceptance Date: 21.03.2018, DOI NO: 10.7456/10802100/015

Research Article - This article was checked by Turnitin

Copyright $(\odot)$ The Turkish Online Journal of Design, Art and Communication 
The established relationship between source and the target domain could be constructed in different extensiveness levels. Analogies can be divided in two according to deepness level of the links as; surface level and deep (structural) (Casakin, 2004). Surface level analogies are considered as links that are easily recognizable; these analogies usually build on physical properties such as an analogy between animals' eye and a car's headlight. On the other hand, deep analogies are constructed on systematic principles between a source and target domain such as an analogy between Velcro and thistles where George de Mestral establishes direct structural mapping between source and target (Gentner and Markman, 1997; Paulos and Jenkins, 2005; Ward, 1998).

Besides the deepness of the connections, the conceptual closeness of the source and design domain is also important for innovation. There is a direct relationship between the distance of the domain and novelty of the design idea. Researchers claim that as the conceptual distance between source and target domains increases the level of innovation and creativity increases as well (Christensen and Schunn, 2007; Lee and LaRose, 2011,Wyche et al., 2006). In his article, Ward (1998) splits analogies according to conceptual distance between source and target domains as mental hops and mental leaps. Researchers have given different names to the same paradigm such as intra-domain and inter domain or local and distant domains (Christensen and Schunn, 2007; Gick and Holyoak, 1980). Close domain, mental leaps and local domain is referring the close domain analogies. For intense, if a designer tries to design a bottle for an olive oil company, creating an analogy with flagons will be a close domain analogy. Intra-domain analogies are usually a result of incremental design ideas. On the other hand, distant domain analogies and mental hops refer to the conceptually distant domain analogies which have a higher possibility of resulting as an innovation in design (Christensen and Schunn, 2007; Paulos and Jenkins, 2005); for example, analogy between shadow play and interactive systems or between thistles and Velcro.

\section{UNDERSTANDING RE-READING IN DESIGN}

Both novice and professional designers usually use close domain analogies and do not or cannot explore the possible design space (Dahl and Moreau, 2002; Golçalves et al., 2011). Research also has shown that novice designers usually create surface level analogies (Paulos and Jenkins, 2005). One reason for the situation could be a designer's tendency to construct analogies on the perceived meaning of the sources. We propose the re-reading in design practice as a guide for designers to have a diverse understanding of the inspiration source. Re-reading in design aims to deconstruct the meaning of the phenomenon or artefact into physical, cultural and personal layers. This division in the meaning mostly reveals new inspirational points from the source since some subtexts may be covered by more solid ones and missed. Those additional subtexts could lead to valuable features and principles for new analogical connections. In our experiences, our re-reading practice is most effective on cultural rituals (traditions) and cultural artefacts due to their deep allegorical representations. Since culture is a combination of different phenomena, they are linked to each other and designers could jump from a single source to other sources for inspiration. In general, a cultural phenomenon is also practiced by different cultures. This provides several new features to designers to use in creating analogies.

In this section, we will examine perception of meaning and deconstruction theory to establish the theoretical bases and define the parameters of re-reading in design.

\section{Meanings of Phenomenon and Artefacts}

We constructed re-reading in design to generate additional meanings from the source of inspiration. Designers, like many people, perceive paradigms as meanings, not pure forms or independent entities. According to semiotics, paradigm meanings are apparent within a context (of other things, relations, situations and other people), which are based on personal and cultural experiences, anticipations and imaginations. In other words, the bidirectional relation of phenomenon/artefact and context constructs the meaning of paradigms (Krippendorff, 2007; Krippendorff, 1989). Therefore, the perceived meaning is combinations of personal and social experiences, anticipations, and imaginations. As a consequence,

Submit Date: 11.10.2017, Acceptance Date: 21.03.2018, DOI NO: 10.7456/10802100/015

Research Article - This article was checked by Turnitin

Copyright $($ ) The Turkish Online Journal of Design, Art and Communication 
all features of the paradigm cannot be seen objectively where meanings are constructed subjectively. So, in our perception some features of the paradigms may be overdrawn or suppressed. As Heraclitus states "the nature of things is hidden from view" (Graham, 2003).

For instance, a sport car does not have the same meaning to a designer who rides a bicycle daily and a designer who drives a car daily. In addition to the socially constructed definition of sports car, which is, generally defined as "sexy, fancy small fast car with two doors", a designer's personal context and association regarding to the sport car is totally different. While a bike rider may see cars as an obstacle and a danger, a racer may see the car as a vehicle of excitement. Therefore, their inspirations will be totally different; these differences in perceived meanings could increase if these designers are part of different cultures and living conditions. We believe that if designers could examine the paradigm outside the combined meaning and separate the meanings of each layer (personal, cultural and physical); they could discover new features and structures that they skipped, to create distant and deep analogies and they could relate those features to different sources to create analogies. Therefore, we propose rereading in design for designers as a complimentary practice to explore the inspiration source space and extract hidden features.

\section{Theoretical Background of Re-reading in Design}

Re-reading is not a new term. The term is self-explanatory. It refers to restudying and reanalyzing the text/artifact with using a different framework and methodology. Re-reading is used in various contents within various disciplines such as literature, music, history and philosophy (Carter, 1997; Derrida, 1981; Glenn and Enoch, 2009; Gross and Walzer, 2000). In the field of history, Glenn and Enoch's approach of analyzing historical writings is an example. They reread the historical text within the context of drama with Burkean framework and crosschecked the historical truths with secondary sources to examine the historic trajectory of rhetoric. Re-reading refers to reanalyzing/restudying a paradigm within a different context. We extended the re-reading term to design as re-reading in design. We defined re-reading in design as an examination of an inspiration source out of a perceived meaning as in rereading. Re-reading in different disciplines are more about investigation of the text/piece for further understanding. On the other hand, re-reading in design is about studying the source for principles and new features that will lead to discovery of new possible connections between design domains to use as analogies. In order to discover new analogies, a designer needs to break the perceived meaning into layers. Derrida extensively studied the meaning of texts and meaning extraction and structured deconstruction theory. This theory may help designers to have a further understanding on the meaning of the artefacts.

Deconstruction theory is based on Derrida's proposition: the text never says what it means or means what it says (Norris and Benjamin, 2002). Writing has traditional constructed rules, which sometimes causes ambiguity in propositions such as French word differences, which means absence/difference/deferral and some occasions spacing, in which one constructs the meaning within the context. Binary propositions seem to be solution for clarity in meaning but there is always a meaning cost due to the reduction. Consider the binary oppositions in colors, assigning each color to white or black; what will define yellow, will it be white like light green? Therefore, even pure binary oppositions used in the meaning of text differs from reader to reader and writers can never be sure what they transmitted exactly (Norris and Benjamin, 2002; Ünlüer and Özcan, 2010). In order to have a better understanding in text, Derrida presented deconstruction, which is referred to as a kind of re-reading. Deconstruction is kind of a reading that is beyond casual reading and examines the subtexts that are vital to support the main text/idea (Cruickshank, 2010). As an example, in order to understand the suppressed meanings in text, Derrida reverses the binary oppositions in the text and uncovers the entities that are suppressed (Lupton and Miller, 1994; Norris and Benjamin, 2002) . Deconstruction theory is not affected only in the context of writing. Design and architecture communities embraced the theory and a movement called deconstructivism emerged.

Submit Date: 11.10.2017, Acceptance Date: 21.03.2018, DOI NO: 10.7456/10802100/015

Research Article - This article was checked by Turnitin

Copyright $(\odot$ The Turkish Online Journal of Design, Art and Communication 
Deconstructionist architects defined deconstructivism as a re-examination of architecture's own language, materials, and processes. In this context, according to Lupton and Miller (1994), deconstructivist architects locate the impurities of structure, which are hidden/repressed by architectural tradition, and draws those impurities to the surface with their own aesthetic touch". Centre Pompidou in Paris, France is a momentary example of deconstructionism where the mechanical structure such as pipes, cables and infrastructure (usually hidden in architectural tradition) of the building is transferred from between the walls to the exterior and revealed as an aesthetic element. Centre Pompidou, deconstructivists deconstructed the building structure -their main output- into elements; and reconstructed it against the traditionally established architectural hierarchies. Therefore, we are inspired from deconstructionist way of redefining the paradigms -the building- by breaking the hierarchies. For re-reading in design, we deconstructed the perceived meaning of the paradigm into 'physical', 'cultural' and 'personal' definitions. Re-reading in design and deconstructionism differ in usage of deconstructed fragments. Unlike deconstructionist architect, we do not recombine the fragments to create new meanings. We use them as features and principles for new design analogies and new source for inspiration sources.

\section{Parameters of Re-reading in Design}

Re-reading in design is an analogy-based inspiration and ideation practice that takes its roots from both re-reading practices and deconstruction theory. In re-reading in design, we analyse the inspiration source out of self-constructed context and deconstruct its hierarchical meaning structure to reveal suppressed features, principles, to breed new inspiration sources and create deep and distant domain analogies. Since features and principles are conveyed within the meaning. We outline our practice in a three-step sequential meaning deconstruction for discovering clandestine features and generate new analogies. We start our exercise by analysing the source's 'physical features' since they are not subjective like cultural and personal meanings and extracted meanings can be used while searching the paradigm's cultural definitions. (1) Physical features which do not vary from person to person and culture-to-culture, such as form, position, and orientation and functioning principles. These features will be less affected by social and personal contexts since personal and social experiences and interpretations are different from culture to culture and person to person. Generally physical feature mappings are the result of surface level analogies. After defining the physical features, we determined (2) 'culturally constructed features' such as cultural features, functions and traditions. To get more inspiration points we encouraged the designers to analyse the similar phenomenon within the same culture or other cultures. Cultural constructed features help designer to understand the paradigm better. Following the method could be extended to the extraction of (3) 'personally constructed futures'. Each paradigm also has personally constructed futures, such as a chocolate may mean a delicious experience for most people; on the other hand, for diabetics it could mean crises or diet. (see Figure 1). In order to support our argument, we will present three case studies.

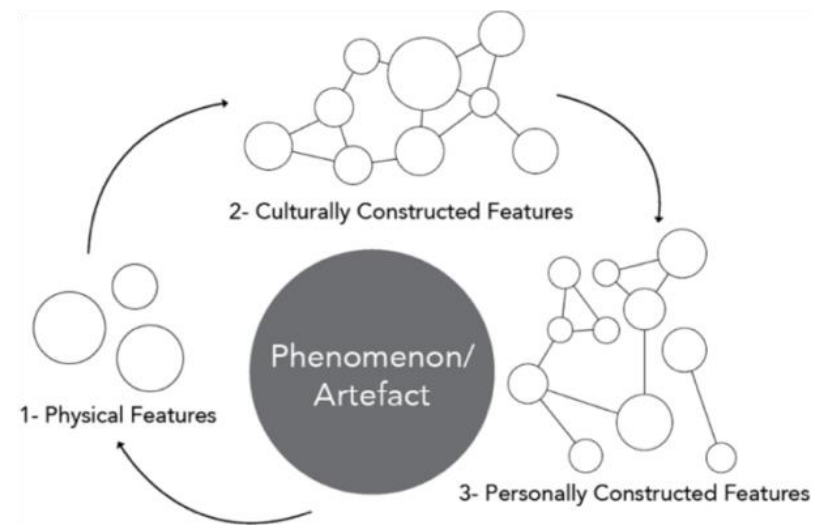

Figure 1. Artefact Meanings and Procedure in Re-reading for Design

Submit Date: 11.10.2017, Acceptance Date: 21.03.2018, DOI NO: 10.7456/10802100/015

Research Article - This article was checked by Turnitin

Copyright $(\odot)$ The Turkish Online Journal of Design, Art and Communication 


\section{CASE STUDIES}

In this section, we present three case studies of re-reading in design and argue the nature of the design approach by examining its outcomes. Here, re-reading in design is used as a 'tool' to extract subtexts and suppressed under the perceived meaning to be used as new inspiration sources in the case studies. As we emphasized before, we worked with small group (5-10) of students in all of our case studies. These studies helped our general understanding on the method in practice and establish the bases for further quantitative studies.

\section{Cultures, the Traditional Shadow Play, and Interactive Media}

In our first case study, we reread traditional shadow play arts by detaching/exploring the artefact's physical, cultural and personal meanings, in order to discover interactive digital medium through cultural phenomenon and design an interactive system through our re-reading outcomes. We searched inspiration sources within history of performing arts for interactive digital artefact. Among several interactive performance arts, we choose to reread shadow plays due to similarities with digital interactive medium such as use of projected images and interaction between performer and spectators (Özcan, 2005). Through our re-reading approach, we analyse the physical and cultural features of shadow play in different cultures. We study the physical features of shadow play from multiple cultures (see Figure 3 for shadow play examples from different cultures) and define the principles regarding to 'seating style', 'light source', 'screen medium', and 'interaction techniques'. These analyses have structured the bases of our inspiration process. We derived inspiration points from each extracted feature, which we could not think in the beginning of the project such as two-sided screen, spatial viewing, performing without screen and creation of atmosphere of actors.

According to our re-reading method, we start to extract the features and principles to use in our design. We started by interpreting the physical structure; (1) the flickering and the changing pattern of light coming from the fire used in the shadow play; (2) the use of the portraits in the shadow play, that are half transparent, half flue, and blurred on the screen because of the intersection of many shadows merging into each other; (3) the use of the special state of being half mobile and half motionless that can be characteristic of puppets; (4) the use of four performance types.

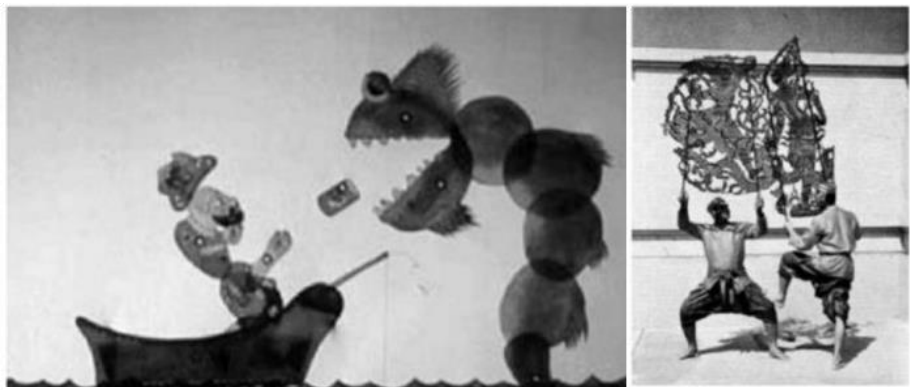

Figure 2. On the right: Turkish Shadow Play; on the left: Wayang Lamah shadow Play

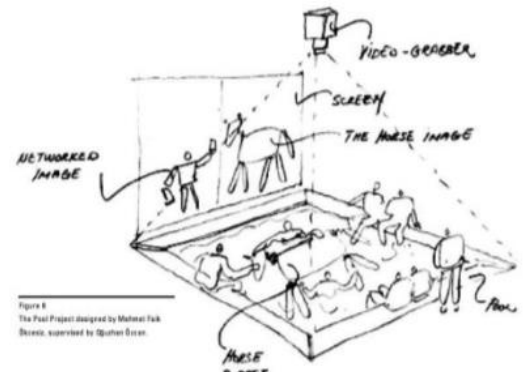

Figure 3. Conceptual sketch of the pool project

We continue to apply re-reading method to get cultural inspirations. We discovered that shadow play is a cultural phenomenon for public communication where spectators sitting and chatting together. This feature provides us a connection with our Anatolian culture of roman baths to use in our piece.

Consequently, we have designed the "Pool Project" by using analogies from the extracted features of shadow play and roman bath culture, which randomly comes up as an external source (design inspiration

Submit Date: 11.10.2017, Acceptance Date: 21.03.2018, DOI NO: 10.7456/10802100/015

Research Article - This article was checked by Turnitin

Copyright $(\odot)$ The Turkish Online Journal of Design, Art and Communication 
method). After practicing re-reading in design on shadow play, we extracted several physical and cultural features from shadow play within multiple cultures by deconstructing its meanings of the phenomenon according to the re-rereading in design principles. Besides extraction of design principles, we mostly benefitted from the linkage between cultural phenomenon. If we did not re-read the shadow play of cultural bases to seek for inspiration sources in the cultural context, we might not have had the chance to make associations with the roman bath culture, which together with the shadow play concept leaded us to the innovative interactive pool project.

\section{Turkish - Ottoman Miniature Art Within the Context of Digital Information Design}

In our second case, we reread Turkish-Ottoman miniature art for getting inspiration for digital information design (Özkan and Doğan, 2013). Miniature, which is mostly known as Islamic art, is actually an information representation method. Due to the concrete techniques of miniature art we decided to make extensive structural analysis instead of making cross-cultural comparisons. We analysed the miniature arts physical principles and derived techniques on mapping of the people and objects, positioning and scaling, informative linkage of elements, symbolization, framing, separating and representation of the temporal environment. We believe that miniature art principles can be implemented to modern information graphics. We found inspiration points such as the use of irregular and multiple screen/frames. We transformed our findings to digital media. In this study, rereading in design helped us in selection of the inspiration source. If we didn't experience the re-reading, we might not have seen the potential of miniature as information representation practice for digital media. Unfortunately, the full potential of re-reading in design has not been applied in this case study, we could have worked out more distant analogies and different inspiration sources if we could define the cultural meanings and make more in-depth analysis. Findings on miniature art are provided for a multimedia design course and the class has been given a task to create multimedia projects considering these findings. As an example, one of the students created the Berlin Wall project (see Figure 4).

\section{Sound and Silence in the Line: Re-Reading Turkish Islamic Calligraphy for Interactive Media Design}

In our third case, we reread khatt art, which is an Islamic calligraphy art that refers to "the art of measured and beautiful writing", for our gestural drawing application (Versos and Coelho, 1997). In the initial steps of our gestural interaction research, considering our previous studies on re-reading in design, knowing the source fullness of traditional arts for inspiration, we search for traditional arts that are performed by body motion. We decided to reread khatt art, which is an Islamic calligraphy art that refers to "the art of measured and beautiful writing", for our gestural drawing application, As we probe into khatt, we figure out the importance of breath and writing rhythm in the process of drawing lines and we created surface analogies using khatt as an inspiration source for a multi touch gesture based drawing application (see Figure 5).

We keep performing the re-reading practice to improve our design, detaching ourselves from the khatt's art practice. We focus on the ritual of the khatt since we plan to make the user to feel full experience of the khatt art. The breathing and the rhythm of the hattats lead us to the relation with sufi music, a kind of a traditional spiritual / Islamic music. We combined sufi music and drawing (see Figure 5). For instance, drawing direction of the lines determines musical notes, thickness of the lines determines octave, length of the line determines length of the note or speed to of drawing determines the volume. 


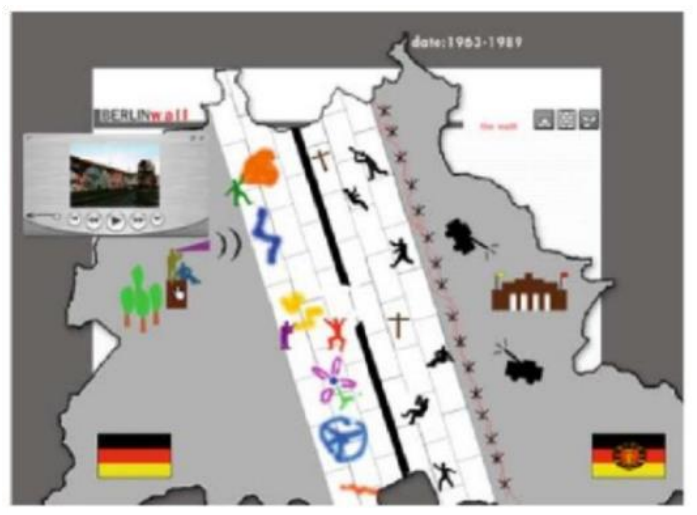

Figure 4. The Berlin Wall Project/Wall Demolition Section by Atike Dicle Peker

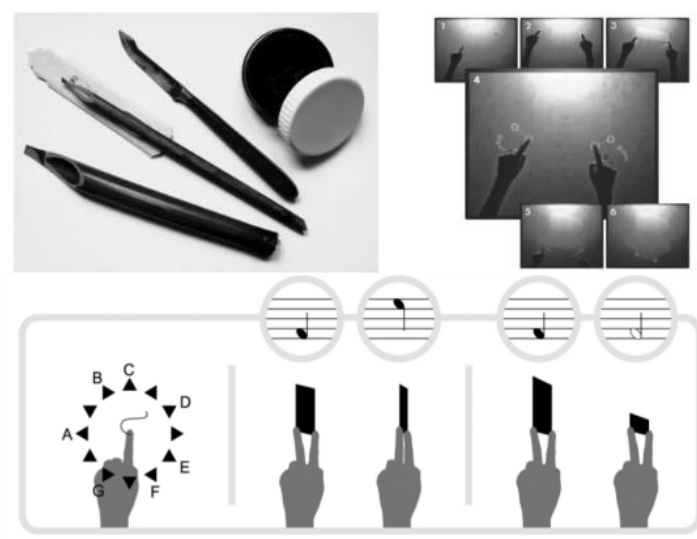

Figure 5. Our inspiration point- khatt materials (upper left); The interaction principles of the system and the relation between sound and image (bottom); Screens from sound and silence (upper right)

We did not use personal meaning deconstruction in this case study since already the piece has so much to express. In order to get more innovative inspirations, we could make cross-cultural analyses. And regardless of the re-reading exercise, selection of the inspiration source that is not related to the design problem would also increase innovation potential.

\section{CONCLUSION}

In essence, we introduce re-reading in design as a complimentary practice for inspiration/ideation to be a guideline that will assist designers in creating deep and distant domain analogies for innovation in their designs. Gonçalves (2011) indicated both novice and professional designers show a tendency to establish surface and close domain analogies that mostly reflects their designs as incremental improvements. According to discussion and experiences summarized above, we understand that rereading could be a complimentary design inspiration practice that reveals suppressed features, inspiration points and principles for designers to create and fortify analogies. The regular analogy process involves the study of the source artefact in terms of physical analysis, such as functions, principles and effects. On the other hand, rereading in design could suggest a further investigation of personal experiences and cultural heritage regarding the inspirational sources to define clandestine principles and discover similar paradigms that project similar feelings, ideas, or functions. This approach may enable one to discover analogies from distant domains by expanding the source like the branches of a tree. Designers may have been applying some of the processes that are defined in the rereading in design practice intuitively; however, the systematic structure of such inspiration/ideation process has not been encountered in the literature.

We have worked with a number of design students to investigate the results of the presented design inspiration guideline; the design processes and outcomes are presented in case studies. These studies were conducted to investigate the nature of the method in practice and establish the bases for further quantitative experiments. Our case studies showed that design students were able to create deep and distant domain analogies with less effort and combine different analogical design logic by expanding their inspirational sources by combining different inspirations that are discovered through re-reading. Moreover, we have discovered that design students benefitted mostly from deconstruction and expansion of cultural meanings of paradigms. Cultural paradigms are often constructed in great detail, experience and intelligence and they are always connected with different cultural paradigms from the same culture and different cultures. 
In our case studies, we worked with different small groups (5-10) of students and in this paper, we summarized student projects as the outcomes of the processes. The case studies helped us to explore the nature of re-reading in design in practice and provided us the experience for extended quantitative studies. We emphasized this point several times in this article because we believe that no further study could be completed without establishing the bases of the studies with these theories and pre-analyses.

\section{ACKNOWLEDGMENTS}

We would like to thank Evren Asım Yantaç for his valuable contributions to this paper.

\section{REFERENCES}

Ball, L.J., Ormerod, T.C., and Morley, N.J. Spontaneous analogising in engineering design: a comparative analysis of experts and novices. Design Studies 25, 5 (2004), 495-508.

Behrens, R. Art, Design and Gestalt Theory. Leonardo 31, 4 (1998), 299-303.

Biskjaer, M., Dalsgaard, P., and Halskov, K. Creativity methods in interaction design. ... on Proceedings of the 1st DESIRE Network Conference on Creativity and Innovation in Design and Innovation, (2010), 12-21.

Brown, T. Design thinking. Harvard business review 86, 6 (2008), 84-92, 141.

Carter, T. Re-Reading Poppea: Some Thoughts on Music and Meaning in Monteverdi's Last Opera. Journal of the Royal Musical Association 122, 2 (1997), 173-204.

Casakin, H. Visual Analogy as a Cognitive Strategy in the Design Process. Expert Versus Novice Performance. Journal of Design Research 4, 2 (2004), 253-268.

Christensen, B.T. and Schunn, C.D. The relationship of analogical distance to analogical function and preinventive structure: the case of engineering design. Memory \& cognition 35, 1 (2007), 29-38.

Cruickshank, L. The Case for a Re-evaluation of Deconstruction and Design: Against Derrida, Eisenman and their Choral Works. (2010), 1-20.

Dahl, D.W. and Moreau, P. The Influence and Value of Analogical Thinking during New Product Ideation. Journal of Marketing Research 39, 1 (2002), 47-60.

Derrida, J. Plato's pharmacy. Dissemination. Trans. Barbara Johnson. Chicago: U of Chicago P 171, (1981).

Dorst, $K$. and Royakkers, $L$. The design analogy: a model for moral problem solving. Design Studies 27, 6 (2006), 633-656.

Gaver, B. Cultural Probes. Interactions 6, 1 (1999), 21-29.

Gentner, D. and Markman, A.B. Structure mapping in analogy and similarity. American psychologist 52, 1 (1997), 45.

Gick, M.L. and Holyoak, K.J. Analogical problem solving. Cognitive Psychology 12, 3 (1980), 306355.

Glenn, C. and Enoch, J. Drama in the archives: Rereading methods, rewriting history. College Composition and Communication, (2009), 321-342.

Goldschmidt, G. and Smolkov, M. Variances in the impact of visual stimuli on design problem solving performance. Design Studies 27, 5 (2006), 549- 569.

Gonçalves, M., Badke-Schaub, P., and Cardoso, C. SEARCHING FOR INSPIRATION DURING

IDEA GENERATION. IASDR2011, the 4th world conference on design research, (2011).

Gonçalves, M., Cardoso, C., and Badke-Schaub, P. What inspires designers?

Preferences on inspirational approaches during idea generation. Design Studies, (2013), 1-25.

Graham, D.W. Does Nature Love to Hide? Heraclitus B123 DK. Classical Philology 98, 2003, 175-

179.

Gross, A.G. and Walzer, A.E. Rereading Aristotle's Rhetoric. SIU Press, 2000.

Halskov, K. Kinds of inspiration in interaction design. Digital Creativity 21, 3 (2010), 186-196.

Hey, J., Linsey, J., Agogino, A., and Wood, K. Analogies and metaphors in creative design.

International Journal of Engineering Education 24, 2 (2008), 1-19.

Submit Date: 11.10.2017, Acceptance Date: 21.03.2018, DOI NO: 10.7456/10802100/015 
The Turkish Online Journal of Design, Art and Communication - TOJDAC

ISSN: 2146-5193, April 2018 Volume 8 Issue 2, p. 364-375

Hutchinson, H., Mackay, W., Westerlund, B., et al. Technology Probes : Inspiring Design for and with Families. Proceedings of the SIGCHI conference on Human factors in computing systems, (2003), 1724.

Krippendorff, $K$. and Butter, R. Semantics: Meanings and Contexts of Artifacts. Departmental Papers (ASC), (2007).

Krippendorff, K. On the Essential Contexts of Artifacts or on the Proposition That "Design Is Making Sense (Of Things). "Design Issues 5, 2 (1989), 9-39.

Ladato, F. The nature of design. Design Management Review 16, 1 (2005), 56-61.

Lee, D. and LaRose, R. The impact of personalized social cues of immediacy on consumers'

information disclosure: a social cognitive approach. Cyberpsychology, behavior and social networking 14, 6 (2011), 337-43.

Lupton, E. and Abbott Miller, J. Deconstruction and graphic design: history meets theory. Visible language 28, (1994), 346.

Moser, C., Fuchsberger, V., and Tscheligi, M. Using probes to create child personas for games. Proceedings of the 8th International Conference on Advances in Computer Entertainment Technology - ACE '11, ACM Press (2011), 1.

Norris, C. and Benjamin, A. What is deconstruction? London: St. 1988. 31. Özcan, O. Cultures, the traditional shadow play, and interactive media design. Design Issues 18, 3 (2002), 18-26.

Özcan, O. Turkish-Ottoman Miniature Art Within the Context of Electronic Information Design Education. International Journal of Technology and Design Education 15, 3 (2005), 237-252.

Ozkan, $O$. and Dogan, F. Cognitive strategies of analogical reasoning in design: Differences between expert and novice designers. Design Studies 34, 2 (2013), 161-192. 34.

Paulos, E. and Jenkins, T. Urban Probes : Encountering Our Emerging Urban Atmospheres. CHI '05 Proceedings of the SIGCHI Conference on Human Factors in Computing Systems, (2005), 341-350.

Sanders, E. Information, inspiration and cocreation. Proceedings of the 6th International Conference of ..., (2005).

Schröder, M. The SEMAINE API: Towards a Standards-Based Framework for Building EmotionOriented Systems. Advances in Human-Computer Interaction 2010, (2010), 1-21.

Ünlüer, A. and Özcan, O. Sound and Silence in the Line: Re-Reading Turkish Islamic Calligraphy for Interactive Media Design. Leonardo, (2010).

Versos, C.A.M. and Coelho, D.A. Biologically Inspired Design : Methods and Validation. Benyus (1997).

Ward, T.B. Analogical distance and purpose in creative thought: Mental leaps versus mental hops. Advances in analogy research: Integration of theory and data from the cognitive, computational, and neural sciences, (1998), 221-230.

Wyche, S., Sengers, P., and Grinter, R.E. Historical Analysis: Using the Past to Design the Future. In P. Dourish and A. Friday, eds., UbiComp 2006: Ubiquitous Computing SE - 3. Springer Berlin, Heidelberg, 2006, 35-51.

Submit Date: 11.10.2017, Acceptance Date: 21.03.2018, DOI NO: 10.7456/10802100/015

Research Article - This article was checked by Turnitin Copyright $($ ) The Turkish Online Journal of Design, Art and Communication 